\title{
Robust optimisation of a single-layer lattice dome
}

\author{
P. Zabojszcza \& U. Radoń \\ Faculty of Civil Engineering and Architecture, Kielce University of Technology, Kielce, Poland \\ P. Tauzowski \\ Department of Information and Computational Science, Institute of Fundamental Technological Research \\ Polish Academy of Sciences, Warsaw, Poland
}

\begin{abstract}
The formulation of deterministic optimization in no way takes into account the randomness of the design variables [Chybiński, M., Garstecki, A. (2017), Czubacki, R., Lewiński T. (2020)]. Optimum structures are particularly sensitive to parameter imperfections. Optimal solutions located on the border of the acceptable area may relatively easily turn out to be completely useless if the parameter values differ from the assumed nominal values. It seems natural to extend the formulation of deterministic optimization, which takes into account the uncertainty of parameter values. Robust optimization proposed in the paper offers such possibilities. In the paper, robust optimisation is discussed on the example of a single-layer lattice covering. After dimensioning the individual groups of bars, the safety level of the structure was assessed by determining the reliability index and failure probability. The structure under analysis is susceptible to stability failure resulting from the condition of the node snap-through. On this basis, a displacement limit function was adopted, which refers to the maximum displacement value at the instant of the node snap-through. Next, two methods of structure optimisation (deterministic and robust), based on analogous constraints and objective function, were compared. The comparison of both methods ends with a reassessment of the safety level of the structure. As a result of robust optimization, a structure with a slightly larger mass was obtained. The difference in the weight of the structure in the case of deterministic and immunity optimization did not exceed $2 \%$. However, the reliability index, which measures the safety of the structure, has increased significantly. At the expense of a slight increase in weight, we obtained a structure that is more reliable and resistant to the dispersion of parameters characterizing the structure's operation.
\end{abstract}

\section{INTRODUCTION}

The notion 'robust design' covers broadly understood methodology of designing structures, devices and also manufacturing processes, which aims to find a solution showing the highest resistance to changes in parameters. At the same time, high functionality of the systems designed is to be maintained. Reduction in the variance of quantities that characterize the structure performance can be achieved by either limiting, or eliminating the scatter of the values of input parameters. In practice, such an approach generates too high costs, making it unviable. A far better method involves a choice of selected design variables made in such a way that a design resistant to parameter variances is obtained, but variances in the structure random parameters do not change. Robust optimisation falls into the methodology category specified above. 


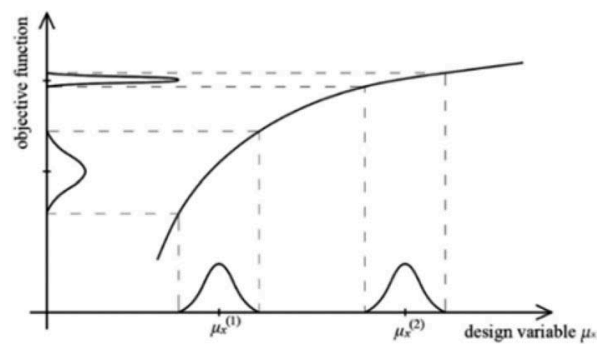

Figure 1. The concept of robust optimisation for a single design variable.

The concept of robust optimisation, shown in Figure 1, is explained on the example of a problem with one design variable $\mathrm{X}$. When a constant variance of the $\mathrm{X}$ random variable is assumed, it can be observed that for the solution $\mu_{\mathrm{X}}{ }^{(2)}$, the objective function variance is decidedly lower than for solution $\mu_{\mathrm{X}}{ }^{(1)}$. In the latter case, the reduction in the average value of the objective function is accompanied by a significant increase in variance.

Robust optimisation represents non-deterministic optimisation formulations. That is due to the fact this approach takes into account the impact of the random nature of the structure parameters on the scatter of the structure response, which usually leads to an increase in the structure reliability. A typical objective function in robust optimisation problem usually includes terms of the mean value, and of variance of the structure response function. Constraints can be deterministic, or can be expressed by the first two statistical moments of response. Contrary to other optimisation types (e.g. reliability optimisation), imprecise determination of types of probability distributions is not of primary importance. The values of the first statistical moments of the structure responses depend primarily on the first moments of random variables. When relevant data are not available, a uniform or normal distribution of variables is often assumed [Błachowski et al. (2020), Tauzowski et al. (2019)]. Interesting modern optimization methods using e.g. genetic algorithms are presented in the paper [Miller, Ziemiański (2020)]. The paper [Rozvany et al (2014)] deals with so-called "optimal plastic design" of trusses with multiple loads, which is based on ultimate load limit principles and requires only statical admissibility of the solution.

\section{PROBLEM FORMULATION}

The aim of robust optimisation is a simultaneous minimization of both the average value and random variation of the objective function. The standard deviation is most often used to describe the scatter. In the formulation below, a two-element vector of the optimisation criteria is found, namely: mean value $\mathbf{E}[\mathrm{f}(\mathbf{d}, \mathbf{X}, \mathbf{P})]$, and standard deviation $\sigma[\mathrm{f}(\mathbf{d}, \mathbf{X}, \mathbf{P})]$, which accounts for multi-criteria optimisation problem formulation. The task of robust optimisation can be formulated as follows:

Find values of variables:

$$
\text { d, } \mu_{\mathbf{x}}
$$

that minimize:

$$
\{\mathbf{E}[\mathrm{f}(\mathbf{d}, \mathbf{X}, \mathbf{P})], \sigma[\mathrm{f}(\mathbf{d}, \mathbf{X}, \mathbf{P})]\}
$$

with the constraints:

$$
\mathbf{E}\left[\mathrm{g}_{\mathrm{i}}(\mathbf{d}, \mathbf{X}, \mathbf{P})\right]-\widetilde{\beta_{\mathrm{i}}} \sigma\left[\mathrm{g}_{\mathrm{i}}(\mathbf{d}, \mathbf{X}, \mathbf{P})\right] \geq 0, \quad \mathrm{i}=1, \ldots, \mathrm{k}_{\mathrm{g}}
$$




$$
\begin{array}{ll}
\sigma\left[\mathrm{c}_{\mathrm{k}}(\mathbf{d}, \mathbf{X}, \mathbf{P})\right] \leq \sigma_{k}^{u}, & \mathrm{k}=1, \ldots, \mathrm{k}_{\mathrm{c}}, \\
\mathrm{d}_{\mathrm{j}}^{l} \leq \mathrm{d}_{\mathrm{j}} \leq \mathrm{d}_{\mathrm{j}}^{u}, & \mathrm{j}=1, \ldots, \mathrm{n}_{\mathrm{d}}, \\
\boldsymbol{\mu}_{\mathrm{x} r}^{l} \leq \boldsymbol{\mu}_{\mathrm{x} r} \leq \boldsymbol{\mu}_{\mathrm{x} r}^{u}, & \mathrm{r}=1, \ldots, \mathrm{n}_{x} .
\end{array}
$$

where: $\mathbf{d}$ - deterministic design variables, $\mathbf{X}, \mathbf{P}$ - vectors of random variables with expected values of $\boldsymbol{\mu}_{\mathrm{x}}, \boldsymbol{\mu}_{\mathrm{p}}, \mathrm{f}-$ objective function, $\mathrm{g}_{\mathrm{i}}$ - functions of constraints $\mathrm{c}_{\mathrm{k}}-$ functions, the standard deviations of which must not exceed the allowable values $\sigma_{\mathrm{k}}^{u}, \beta_{\mathrm{i}}>0$ - coefficients corresponding to the constraints $\mathrm{g}_{\mathrm{i}} \geq 0$ which represent the safety margin with which these constraints must be met.

The concept of constraints is shown in Figure 2. While solving the problem of robust optimisation, it is sought that, at the optimum point, the mean values of the constraint functions $\mathrm{g}_{\mathrm{i}}$, $\mathrm{i}=1, \ldots, \mathrm{k}_{\mathrm{g}}$, should be shifted away from zero by at least $\widetilde{\beta_{\mathrm{i}}}$ standard deviations. A very popular way to solve multi-criteria optimisation tasks is to employ the problem scalarization method. In the method, a linear combination of criteria is used as an objective function. Consequently, the problem (7) - (12) can be modified to obtain the following scalar optimisation problem:

Find values of variables:

$$
\text { d, } \mu_{\mathbf{x}}
$$

that minimize:

$$
\widetilde{\mathrm{f}}=\frac{1-\alpha}{\boldsymbol{\mu}^{*}} \mathbf{E}[\mathbf{f}(\mathbf{d}, \mathbf{X}, \mathbf{P})]+\frac{\alpha}{\sigma^{*}} \sigma[\mathrm{f}(\mathbf{d}, \mathbf{X}, \mathbf{P})]
$$

with the constraints:

$$
\begin{array}{lr}
\mathbf{E}\left[\mathrm{g}_{\mathrm{i}}(\mathbf{d}, \mathbf{X}, \mathbf{P})\right]-\widetilde{\beta_{\mathrm{i}}} \sigma\left[\mathrm{g}_{\mathrm{i}}(\mathbf{d}, \mathbf{X}, \mathbf{P})\right] \geq 0, & \mathrm{i}=1, \ldots, \mathrm{k}_{\mathrm{g}}, \\
\sigma\left[\mathrm{c}_{\mathrm{k}}(\mathbf{d}, \mathbf{X}, \mathbf{P})\right] \leq \sigma_{\mathrm{k}}^{u}, & \mathrm{k}=1, \ldots, \mathrm{k}_{\mathrm{c}}, \\
\mathrm{d}_{\mathrm{j}}^{l} \leq \mathrm{d}_{\mathrm{j}} \leq \mathrm{d}_{\mathrm{j}}^{u}, & \mathrm{j}=1, \ldots, \mathrm{n}_{\mathrm{d}}, \\
\mu_{\mathrm{x} r}^{l} \leq \mu_{\mathrm{x} r} \leq \mu_{\mathrm{x} r}^{u}, & \mathrm{r}=1, \ldots, \mathrm{n}_{x} .
\end{array}
$$

The weight coefficient $\alpha \in[0,1]$, found in formula (8), specifies the relevance of each of the criteria, whereas $\mu^{*}$ and $\sigma^{*}$ are normalizing constants. Assuming $\alpha=0$, the optimisation problem is converted into a typical task of minimising the mean value. For $\alpha=1$, however,

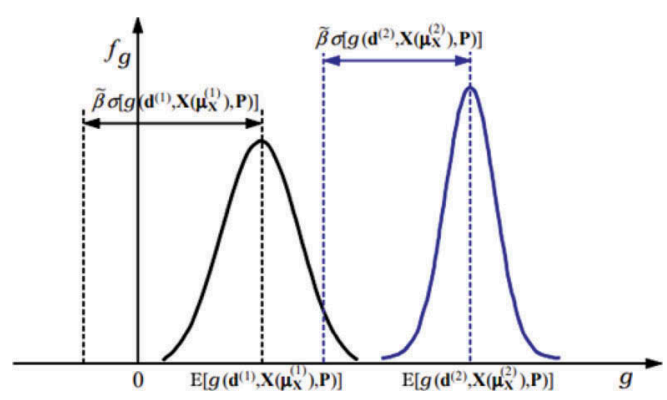

Figure 2. The concept of constraints in the robust optimisation. 
optimisation becomes the problem of minimising the objective function variance. A key element of the algorithm employed to perform the robust optimisation task involves an effective method of estimating mean values and standard deviations of the objective function and the constraint function [Stocki et al. (2012)].

\section{EXAMPLE}

In the study, a steel single-layer lattice dome loaded with force $\mathrm{P}=3.665 \mathrm{kN}$ at each node was analysed. The members of the dome were designed to be made of S235 steel, with yield strength $\mathrm{f}_{\mathrm{y}}=235 \mathrm{MPa}$, Young's modulus $\mathrm{E}=210 \mathrm{GPa}$ and Poisson index $\mathrm{v}=0.3$. The geometry of the dome of concern is shown in Figure 3 and Table 1. The weight of the structure modelled is Mass $=813.5139 \mathrm{~kg}$.

In the structure, three groups of bars were specified as shown in Table 2.

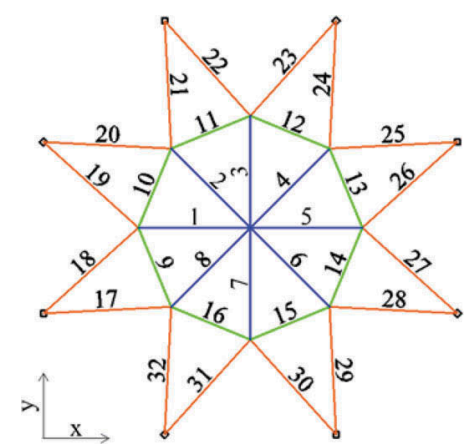

Figure 3. The lattice dome geometry.

Table 1. The lattice dome geometry.

\begin{tabular}{|c|c|c|c|c|c|c|c|}
\hline \multirow{2}{*}{$\begin{array}{l}\text { Node } \\
\text { number }\end{array}$} & $X$ & $\mathrm{Y}$ & Z & \multirow{2}{*}{$\begin{array}{l}\text { Node } \\
\text { number }\end{array}$} & $\mathrm{X}$ & $\mathrm{Y}$ & $\mathrm{Z}$ \\
\hline & {$[\mathrm{cm}]$} & {$[\mathrm{cm}]$} & {$[\mathrm{cm}]$} & & {$[\mathrm{cm}]$} & {$[\mathrm{cm}]$} & {$[\mathrm{cm}]$} \\
\hline 1 & 646.716 & 646.716 & 46.000 & 10 & 378.837 & 1293.431 & 0.0 \\
\hline 2 & 646.716 & 996.716 & 34.000 & 11 & 914.594 & 1293.431 & 0.0 \\
\hline 3 & 894.203 & 894.203 & 34.000 & 12 & 1293.431 & 914.594 & 0.0 \\
\hline 4 & 996.716 & 646.716 & 34.000 & 13 & 1293.431 & 378.837 & 0.0 \\
\hline 5 & 894.203 & 399.228 & 34.000 & 14 & 914.594 & 0.0 & 0.0 \\
\hline 6 & 646.716 & 296.716 & 34.000 & 15 & 378.837 & 0.0 & 0.0 \\
\hline 7 & 399.228 & 399.228 & 34.000 & 16 & 0.0 & 378.837 & 0.0 \\
\hline 8 & 296.716 & 646.716 & 34.000 & 17 & 0.0 & 914.594 & 0.0 \\
\hline 9 & 399.228 & 894.203 & 34.000 & & & & \\
\hline
\end{tabular}

Table 2. Cross-sections adopted for individual groups of bars.

\begin{tabular}{lll}
\hline Group name & Bar numbers & Profile \\
\hline Meridian_1 (Blue) & 1 to 8 & RO54 $\times 3.6$ \\
Meridian_2 (Orange) & 17 to 32 & RO60.3 6.3 \\
Ring (Green) & 9 to 16 & RO51x6.3 \\
\hline
\end{tabular}


Table 3. Values of axial forces and load capacity for the most stressed members of the structure and values of the maximum vertical and horizontal displacements for nodes 2-9.

\begin{tabular}{llll}
\hline Internal force/Load capacity & $\begin{array}{l}\text { Meridian_1 } \\
\text { Bar no. } 7\end{array}$ & $\begin{array}{l}\text { Meridian_2 } \\
\text { Bar no. 30 }\end{array}$ & $\begin{array}{l}\text { Ring Bar } \\
\text { no. 15 }\end{array}$ \\
\hline Ned [kN] - axial force & 12.664 & 25.093 & 31.976 \\
Strength utilisation [\%] & 46 & 55 & 56 \\
Maximum vertical displacement [mm] & 1.071 & & \\
Allowable vertical displacement [mm]-D/300 & 4.667 & & \\
Maximum horizontal displacement [mm] & 0.06 & & \\
Allowable horizontal displacement [mm] - H/150 & 0.307 & & \\
\hline
\end{tabular}

Table 3 collates the values of internal forces and load capacity for the most stressed elements of individual bar groups and limit values of displacements of nodes 2 to 9 .

\subsection{Reliability analysis}

The first stage involved structure reliability analysis in which the Monte Carlo method was used. Geometric characteristics of cross-sections ( $A_{\mathrm{i}}$ - area of successive bar groups) and heights of individual structure nodes $(Z i)$ were assumed as random variables. The description of random variables is shown in Table 4 . The variables are not correlated.

The structure under analysis is susceptible to stability failure resulting from the condition of the node snap-through. On this basis, a displacement limit function was adopted, which refers to the maximum displacement value at the instant of the node snap-through:

$$
\mathrm{f}_{\mathrm{s}}=1-\frac{w(\mathbf{x})}{\mathrm{W}_{\max }}=1-\frac{w(\mathbf{x})}{1.841}
$$

where: $w(\mathbf{x})$ - node 2 displacement, $\mathrm{w}_{\max }$ - node 2 displacement at the instant of the snapthrough.

The value of the reliability index, at the instant the structure was loaded with force $\mathrm{P}=$ $3.665 \mathrm{kN}$, was $\beta=2.138$, whereas the failure probability was $\mathrm{p}_{\mathrm{f}}=0.016$.

\subsection{Deterministic optimisation}

The second stage involved the deterministic optimisation. The design variables were crosssectional areas of the individual bar groups. The following notation was adopted for the variables: Meridian_1: A1, Meridian_2: A2, and Ring: A3. The objective function was the structure weight:

Table 4. Description of random variables.

\begin{tabular}{|c|c|c|c|c|c|c|c|}
\hline \multirow{2}{*}{$\begin{array}{l}\text { Random } \\
\text { variables } X_{\mathrm{i}}\end{array}$} & $\begin{array}{l}\text { Mean } \\
\text { values }\end{array}$ & $\begin{array}{l}\text { Standard } \\
\text { deviation }\end{array}$ & $\begin{array}{l}\text { Variation } \\
\text { coefficient }\end{array}$ & \multirow{2}{*}{$\begin{array}{l}\text { Random } \\
\text { variables } X_{\mathrm{i}}\end{array}$} & $\begin{array}{l}\text { Mean } \\
\text { values }\end{array}$ & $\begin{array}{l}\text { Standard } \\
\text { deviation }\end{array}$ & $\begin{array}{l}\text { Variation } \\
\text { coefficient }\end{array}$ \\
\hline & {$[\mathrm{cm}]$} & {$[\mathrm{cm}]$} & {$[\%]$} & & {$[\mathrm{cm}]$} & {$[\mathrm{cm}]$} & {$[\%]$} \\
\hline$A_{1}$ & 5.7 & 0.285 & 5 & $Z 4$ & 34 & 0.34 & 1 \\
\hline$A_{2}$ & 10.7 & 0.535 & 5 & $Z 5$ & 34 & 0.34 & 1 \\
\hline$A_{3}$ & 8.85 & 0.443 & 5 & Z6 & 34 & 0.34 & 1 \\
\hline$Z 1$ & 46 & 0.46 & 1 & $Z 7$ & 34 & 0.34 & 1 \\
\hline$Z 2$ & 34 & 0.34 & 1 & $Z 8$ & 34 & 0.34 & 1 \\
\hline$Z 3$ & 34 & 0.34 & 1 & $Z 9$ & 34 & 0.34 & 1 \\
\hline
\end{tabular}




$$
\mathrm{f}_{\mathrm{C}}=\operatorname{minimum}(\text { Mass })
$$

Simple constraints are shown in Table 5. They constitute the upper and lower boundary of the design variables being sought.

The inequality constraint was formulated as a condition of non-exceedance of the allowable node vertical displacement:

$$
\mathrm{g}(\mathbf{x})=w-\mathrm{w}_{\max }=\mathrm{w}-1.841<0
$$

The deterministic optimisation was carried out using the Nelder Mead simplex method at the maximum number of iterations $\mathrm{N}=1000$, and the convergence parameter $\epsilon=1.0 \mathrm{E}-08$.

The dimensions of cross-sections obtained for individual bar groups are summarised in Table 6. The value of the objective function was $f_{C}=772.924 \mathrm{~kg}$. The failure probability and the reliability index, which in this case amounted to: $\mathrm{p}_{\mathrm{f}}=0.034, \beta=1.824$, respectively, were also verified.

\subsection{Robust optimisation}

As regards robust optimisation, random variables, design variables, the objective function and constraints were defined. The value of the variation coefficient was set at $5 \%$. For the case of concern, the robust optimisation task takes on the following form:

1. Find the values of variables: $A 1, A 2, A 3$

2. That minimise: $\mathrm{f}_{\mathrm{C}}=\frac{1-\alpha}{\eta *} \mathbf{E}[$ Mass $]+\frac{\alpha}{\sigma *} \boldsymbol{\sigma}[$ Mass $]$

3. With the constraints:

$$
\begin{aligned}
& \mathbf{E}[w-1.841]-\beta \cdot \boldsymbol{\sigma}[w-1.841] \geq 0 \\
& 5.415 \leq R 1 \leq 5.985 \\
& 10.165 \leq R 2 \leq 11.235 \\
& 8.408 \leq R 3 \leq 9.293
\end{aligned}
$$

where: $\alpha \in[0,1]$ - specifies the relevance of each of the criteria, $\eta *, \sigma *$ - normalizing constants, $w$-1.841 - constraint on the allowable vertical displacement.

The dual response area method and the strategy of statistical approximation were employed. The parameters adopted were: $\alpha=0.5, \beta=2.0$. Dual response areas were

Table 5. Description of simple constraints.

\begin{tabular}{lll}
\hline Design variable & Lower boundary $[\mathrm{cm}]$ & Upper boundary $[\mathrm{cm}]$ \\
\hline$A 1$ & 5.415 & 5.985 \\
$A 2$ & 10.165 & 11.235 \\
$A 3$ & 8.408 & 9.293 \\
\hline
\end{tabular}

Table 6. Values of the design variables produced with deterministic optimization.

\begin{tabular}{ll}
\hline Random variable & Optimum value $[\mathrm{cm}]$ \\
\hline A1 & 5.415 \\
A2 & 10.167 \\
A3 & 8.408 \\
\hline
\end{tabular}


Table 7. Values of design variables obtained in the robust optimisation.

\begin{tabular}{ll}
\hline Random design variable & Optimum mean value $[\mathrm{cm}]$ \\
\hline A1 & 5.426 \\
A2 & 10.216 \\
A3 & 8.793 \\
\hline
\end{tabular}

constructed using the the Kriging method, while the experiments were designed in accordance with optimum Latin hyper-cube sampling. To solve the optimisation problem of concern, i.e. to minimise the $\mathrm{f}_{\mathrm{C}}$ function, the Nelder Mead simplex algorithm was applied.

The robust optimisation yielded the following values of the design variables shown in Table 7. In this case, the structure weight was $\mathrm{f}_{\mathrm{C}}=782.076 \mathrm{~kg}$. The robust optimisation type produced the structure weight that was slightly higher compared with that obtained with the deterministic optimisation. The reliability index increased and the failure probability decreased compared with the deterministic optimisation, for which the values were $\beta=1.951$ and $\mathrm{p}_{\mathrm{f}}=0.026$.

\section{SUMMARY}

In the example above, two methods of structure optimisation, based on analogous constraints and objective function, were compared. At the initial stage of the design, the cross-section dimensions adopted were $\mathrm{A} 1=5.7 \mathrm{~cm}^{2}, \mathrm{~A} 2=10.7 \mathrm{~cm}^{2}, \mathrm{~A} 3=8.85 \mathrm{~cm}^{2}$. The reliability index for this design situation was $\beta=2.138$. In the deterministic optimisation carried out with the Nelder-Mead simplex method, new dimensions of cross-sections were determined. A decrease in the structure weight by approx. $5 \%$ was observed. Modification of the areas led to a decrease in the reliability index to the value of $\beta=1.824$.

As a result of robust optimization, a structure with a slightly larger mass was obtained. The difference in the weight of the structure in the case of deterministic and immunity optimization did not exceed $2 \%$. However, the reliability index, which measures the safety of the structure, has increased significantly. At the expense of a slight increase in weight, we obtained a structure that is more reliable and resistant to the dispersion of parameters characterizing the structure's operation.

\section{REFERENCES}

Błachowski, B., Tauzowski, P., Logo, J., 2020, Yield limited optimal topology design of elastoplastic structures, Structural and Multidisciplinary Optimization, Vol. 61, p. 1953-1976.

Chybiński, M., Garstecki, A., 2017, Optimal rib configuration in steel welded beams and its robustness, CMM - 22nd Computer Methods in Mechanics September 13th-16th 2017, Lublin, Poland.

Czubacki, R., Lewiński, T., 2020, Optimal archgrids: a variational setting. Struct Multidisc Optim 62, 1371-1393, DOI:10.1007/s00158-020-02562-y.

Miller, B., Ziemiański, L., 2020, Optimization of dynamic behavior of thin-walled laminated cylindrical shells by genetic algorithms and deep neural networks supported by modal shape identification, Advances in Engineering Software, Volume 147, DOI: 10.1016/j.advengsoft.2020.102830, ISSN 09659978.

Rozvany, G.,I.,N., Sokół, T., Pomezanski, V., 2014, Fundamentals of exact multi-load topology optimization - stress-based least-volume trusses (generalized Michell structures) - Part I: Plastic design., Struct Multidisc Optim 50, 1051-1078, DOI: 10.1007/s00158-014-1118-7.

Stocki, R., Szolc, T., Tauzowski, P., Knabel, J., 2012, Robust design optimization of the vibrating rotor-shaft system subjected to selected dynamic constraints, Mechanical Systems and Signal Processing, Vol. 29, p. $34-44$.

Tauzowski P., Błachowski B., Logo J., 2019, Functor-oriented topology optimization of elasto-plastic structures, Advances in Engineering Software, Vol. 135. 